\title{
Palynofloral patterns of terrestrial ecosystem change during the end-Triassic event - a review - ERRATUM
}

doi: 10.1017/S0016756815000552 Published online by Cambridge University Press 7 September 2015

Keywords:

end-Triassic mass extinction; Triassic-Jurassic boundary; terrestrial palynology; ecological severity

In Figure 1 in the above article locality number 6 and 8 have erroneously switched places. The author sincerely apologizes for this error and gratefully acknowledges the journal for printing this erratum. Please see the corrected Figure 1 below.

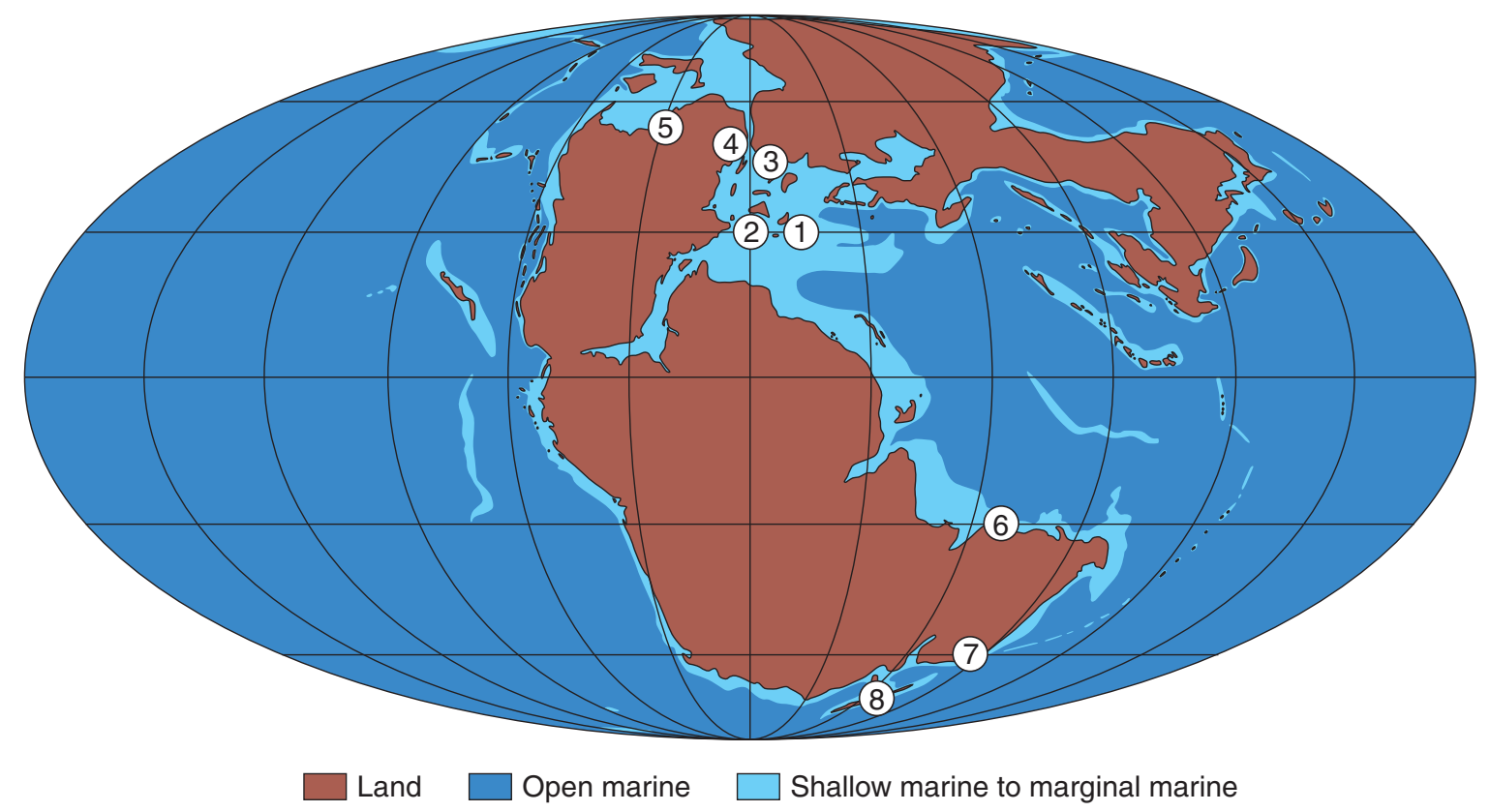

Figure 1. (Colour online)

\section{Reference}

LindSTRÖM, S. 2016. Palynofloral patterns of terrestrial ecosystem change during the end-Triassic event - a review. Geological Magazine 153, 223-251. doi:10.1017/S0016756815000552 